\title{
Accommodations on Reading Comprehension Assessment for Students with Learning Disabilities: A Review Study
}

\author{
Georgia Andreou, Panagiota Athanasiadou*, Sotiria Tzivinikou \\ Department of Special Education, University of Thessaly, Thessaly, Greece \\ Email: andreou@uth.gr, *atyiota@hotmail.com, sotitzivi@uth.gr
}

How to cite this paper: Andreou, G., Athanasiadou, P., \& Tzivinikou, S. (2019). Accommodations on Reading Comprehension Assessment for Students with Learning Disabilities: A Review Study. Psychology, 10, 521-538.

https://doi.org/10.4236/psych.2019.104034

Received: January 4, 2019

Accepted: March 12, 2019

Published: March 15, 2019

Copyright $\odot 2019$ by author(s) and Scientific Research Publishing Inc. This work is licensed under the Creative Commons Attribution International License (CC BY 4.0).

http://creativecommons.org/licenses/by/4.0/

\begin{abstract}
Students with learning disabilities face severe difficulties in a number of academic domains, such as phonological awareness, oral or written speech comprehension, time management, processing of information and organization of strategies to solve academic problems. This group of students constitutes a large category and even if they receive differentiated teaching, they fail to successfully perform in examinations. Therefore, the effectiveness of accommodations in the reading comprehension assessment of students with learning disabilities has been extensively studied the last ten years. Researchers verify the efficiency of the most frequently implemented accommodations-the administration of extended time and the read-aloud accommodation-and investigate new accommodations that aim at accurately depicting the performance of students with learning disabilities. To ensure assessment fairness and validity of accommodated tests, it has been proposed under the principles of interaction theory that these accommodations should not lead to changes in typical students' performance. The purpose of this paper is to present the findings of recent research in the field of accommodations on reading comprehension assessment, discuss their effectiveness in the context of the interaction theory and provide support for the significance of test accommodations for students with learning disabilities. The effectiveness of extended time and read aloud accommodations is confirmed by the results of the researches; however it is concluded that further investigation on additional accommodations is essential, so that different needs and difficulties be accommodated appropriately.
\end{abstract}

\section{Keywords}

Learning Disabilities, Assessment, Reading Comprehension, Test Accommodations Interaction Theory 


\section{Introduction}

Reading comprehension is a complex procedure which plays a significant role in the academic, professional and social success of students and adults and demands the automaticity of the so-called "lower" cognitive processing skills, such

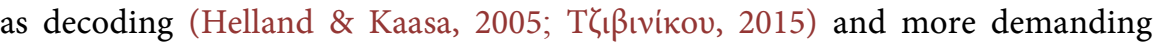
cognitive skills (Kuhn, Schwanenflugel, \& Meisinger, 2010), such as self-regulation techniques (Dermitzaki, Andreou, \& Paraskeva, 2008). Due to the complexity of the procedure, reading comprehension cannot be easily assessed, as there are numerous skills that must be synchronized while comprehending a text (Harley, 2014), rendering standard test formats inadequate to assess the competence of these skills. The situation is even more demanding for students with learning disabilities who often face severe reading problems, making reading comprehension a difficult task for them both in the teaching and in the assessment process (Torgesen, 2006). Apart from the reading difficulties of students with learning disabilities, there are a lot of students diagnosed with specific reading disability who face severe difficulties in decoding, reading fluency (Shaywitz \& Shaywitz, 2005), memory span, inference making, self-regulation techniques (Zimmerman, 2002) and time management (Shaywitz \& Shaywitz, 2005).

Nowadays, due to the growing number of students with learning disabilities and particularly specific reading disability in classrooms (Hulme \& Snowling, 2011), there is an attempt from the teachers and the educational institutions of various countries to offer differentiated teaching. Differentiated teaching refers to the inclusion of more experiential ways of learning and instruction of learning techniques (Torgesen, 2006) aiming at compensating for the difficulties students with learning disabilities face in the process of learning. Furthermore, there is an attempt to offer accommodations regarding the assessment of these students (Sireci, Li, \& Scarpati, 2003), such as extended time during exams, since even if they receive differentiated teaching, they still perform poorly in standard tests. This fact delineates the need for differentiation in tests administration which will take into account the characteristics of the students with learning disabilities and enable them to show their full potential during the process of the exams.

Assessment of students with learning disabilities is a procedure which demands careful planning. It has been proven that students with reading disabilities underperform in standard tests, a fact that makes them feel less confident, leading them to quit the effort of academic advancement (Alexander-Passe, 2006). Consequently, a number of researches were conducted in order to assess the effectiveness of various test accommodations for students with learning disabilities and to promote fairer assessment (Schneider, Gong, \& Egan, 2016). The majority of accommodations refer to the additional time that is given to students with learning disabilities or to the oral presentation of certain parts of the tests, in an effort to adapt material to students' learning profile; the learning profile being the focal point in the learning (Eide \& Eide, 2006) and assessment procedure.

Another issue that preoccupies researchers is if the accommodations that are 
offered to students with learning disabilities improve the performance of only these students and not of their typical peers, so that it can be ensured that accommodations offer fair and valid assessment. Following this concern, the interaction theory has been proposed supporting the fact that accommodations must benefit only students with special educational needs and not typically developing students (Sireci, Li, \& Scarpati, 2003).

Most of the studies on assessment accommodations that will be reviewed were conducted in the mother tongue of each researcher; English being the most frequent. Furthermore, the majority of participants in the researches that will be discussed are students of primary and secondary education that face learning difficulties. As far as the accommodations are concerned, Thurlow, Lazarus, Thompson, \& Morse (2005) state that there are five types of accommodations; differentiation in timing, differentiation in the way of responding, differentiation in the test surroundings, differentiation in the material provided and differentiated presentations of the test. The most frequent accommodations refer to the administration of extended time and the read aloud accommodation. In view of the above, the purpose of this paper is to review a number of recent researches (after 2000) conducted on accommodations used in reading comprehension assessment for students with learning disabilities, so as to present the variety of implemented accommodation and their efficiency, and discuss them in the light of the interaction theory.

\section{Read Aloud Accommodation}

The most widely researched accommodation is the read aloud accommodation which refers to the oral presentation of the whole test or parts of it (Sireci, Li, \& Scarpati, 2003). Weston's (2002) study discusses the positive effects of readaloud accommodation to a sample of $4^{\text {th }}$ grade students who undertook a maths test (calculations and word problems) under the standard and the read aloud accommodation. Although the study refers to a maths test, it provides significant insights on reading comprehension assessment.

The read-aloud accommodation involved the oral presentation of the test questions and choices by the teachers. Students were also administered the first part of Terra Nova Reading Test which assessed their reading ability and academic level (Weston, 2002), so as to draw conclusions on reading comprehension and performance in tests demanding the use of this skill. In addition, teachers were asked their beliefs on the accommodation and its effectiveness. The findings of the study supported that the read aloud accommodation benefited students with learning disabilities more than their typical peers and students with mild reading difficulties who presented mixed results under the two formats. It was concluded that the less proficient in reading were the students, the more the gains, since listening to the test compensated for their decoding difficulties, comprehension deficits and even engagement in the test (Weston, 2002). 
Moving to studies on reading comprehension per se, Randall \& Engelhard (2010) conducted a long term study on the read-aloud accommodation and resource guide, in $4^{\text {th }}$ and $7^{\text {th }}$ grade Georgia students. The participants were tested in the $3^{\text {rd }}$ and $6^{\text {th }}$ grade through a standard achievement test that also assessed reading comprehension, and in the next grade they completed the corresponding test under one of two kinds of accommodations or under the standard administration. The participants were students with and without learning disabilities and they were assigned randomly to one of the three types of administration (Randall \& Engelhard, 2010). One accommodation was the use of a resource book, that will be discussed in the section Other accommodations and the other accommodation was the read-aloud accommodation of all texts and questions.

It was concluded that students with learning disabilities in all grades, except the $7^{\text {th }}$ grade where improvement in performance was observed in both groups, benefitted from the read aloud accommodation more than their typical peers, presenting a differential boost (Randall \& Engelhard, 2010). According to the researchers, this may suggest that the read aloud accommodation is more indicative of the performance of younger students. However, researchers stated a number of limitations concerning their study, such as the lack of motivation in being retested, which may have affected students' performance in the second administration of the test (Randall \& Engelhard, 2010).

However, a number of studies present contradictory results, as far as the extent of improvement the read-aloud accommodation offers to students with learning disabilities, but they were quite unanimous as regards its positive effects. Such a research on read aloud accommodation was conducted by Crawford \& Tindal (2004). The participants of the study were $4^{\text {th }}$ and $5^{\text {th }}$ graders, typical students and students with learning disabilities. They completed a reading test under the standard format and the accommodated one, which involved the use of video. More specifically, the students watched a monitor in which the text was read by a researcher and then the comprehension questions and the answers were presented orally and visually (Crawford \& Tindal, 2004). The results indicated that the majority of students with and without learning disabilities benefitted from this accommodation; though to a different extent (Crawford \& Tindal, 2004), rendering the research on individualized profiles of students urgent to reach conclusions on the effectiveness of accommodations.

Furthermore, the study of Meloy, Deville, \& Frisbie (2000), during which selected texts from the Iowa Test of Basic Skills (ITBS) achievement test were administered to middle school students randomly assigned to standard or readaloud format showed that the latter led to significantly better results for both typical students and students with specific reading disability. The results of the aforementioned study did not verify interaction theory, and due to the extent of the improvement, Meloy, Deville, \& Frisbie (2000) proposed that more research should be conducted on accommodations that would be more indicative of the students' performance as far as reading comprehension is concerned. 
Kosciolek \& Ysseldyke (2000) conducted a research on the read aloud accommodation on 17 typical students and 15 students in special education of $3^{\text {rd }}$ to $5^{\text {th }}$ grade. The students were administered both the standard and the accommodated version of California Achievement Tests (CAT/5), Comprehension Survey. In the accommodated version the students listened to a text from an audiocassette player. The results of the research showed that typically developing students outperformed the students with learning disabilities in both tests; however, the latter group presented improvement in the accommodated format, whereas typical students did not show any significant difference. Nonetheless, it is concluded that there was no statistically significant interaction between participants' learning profile and type of administration, rendering research on bigger groups highly significant (Kosciolek \& Ysseldyke, 2000).

Dolan, Hall, Banerjee, Chun, \& Strangman (2005) examined the effect of computer-based read aloud accommodation on ten students of $11^{\text {th }}$ and $12^{\text {th }}$ grade with specific learning disabilities. Participants were presented with history and civics test that also assessed their reading comprehension skill both in paper-pencil form and computer-based read aloud format. The test included 22 texts with multiple choice questions. Both formats included two additional accommodations, the presentation of one test item at a time and the absence of a separate answer sheet for the students to mark their answers (Dolan et al., 2005). The participants were trained in the use of the computer-based system, before the administration of the test. Interviews were also used to investigate the preferences of students while using the computer-based system. The test was counterbalanced across four randomly organized groups in terms of order (paper to pencil format and computer-based format) and test form (form A and B) (Dolan et al., 2005).

The results of the study verified the beneficial effect of the read-aloud accommodation for reading comprehension compared to the standard format, only for longer texts, since texts of 100 words and below are not perceived so challenging even by students with learning disabilities (Dolan et al., 2005). The researchers concluded that a read-aloud accommodation through the use of technology offers more possibilities to students than the teacher oriented read-aloud accommodation, which is affected by each teacher's personal reading style and speed. Additionally, researchers supported that technology increases students' engagement (Dolan et al., 2005). Supportive information on the additional technology oriented options of this accommodation, apart from the text to speech option, will be provided in the section Technology Oriented Accommodations.

Brown \& Augustine (2001) also examined technology-oriented read aloud accommodation through screen reading software (Authorware 5.0) in students with and without reading disabilities, completing science and social studies assessment. Authorware 5.0 enabled participants to listen to test items as many times as they needed. Half of the students began with the software format while the other half with the pencil-paper format. The researchers concluded that 
there was no overall statistically significant difference between the two formats as far as reading performance is concerned. However, it has been suggested that the students' lack of knowledge on social studies and science, which is achieved primarily through the use of the reading skill in which they present difficulties, may have affected the results of poor readers and not their reading comprehension competence per se (Brown \& Augustine, 2001).

On the other hand, Elbaum, Arguelles, Campbell, \& Saleh (2004) conducted a research on assessing the read aloud accommodation, compared to the standard format, on a reading comprehension test for students of middle and high school with and without learning disabilities. In the accommodated format students were asked to read the text, the questions and all the possible answers before they reach their final decision. Loud reading helps learning disabled students monitor their decoding difficulties by correcting the mistakes they listen to while reading a text (Elbaum et al., 2004). The researchers concluded that neither group showed positive differences in the performance between the two formats. Nevertheless, students with learning disabilities presented greater variability, either positive or negative, as far as their reaction to the accommodation is concerned (Elbaum et al., 2004). Due to some students' underperforming in the accommodated format, the researchers suggested that more thorough organization, individualized insights and testing of the effectiveness of the accommodations applied is urgent.

\section{Extended Time Accommodation}

In the review of Sireci, Li, \& Scarpati (2003), extended time is referred to as the most common accommodation in various academic domains, such as reading comprehension and maths, leading both typical students and students with learning disabilities to better results, the latter presenting greater improvement than the former. The aforementioned statement has been confirmed by a number of studies.

In Huesman \& Frisbie's (2000) study, typical students and students with learning disabilities from two districts completed the Iowa Test of Basic Skills Reading Comprehension Test under its standard and "extended time" version, except for 68 learning disabilities students (LD) who completed the test only under extended time version due to data collection inconsistencies. More specifically, as far as the LD group is concerned, there were two groups based on the administration they received. The first group completed the test under both conditions while the second only under the extended time administration. Furthermore, participants without learning disabilities (NLD) formed two groups based on their distinct district, completing the test under both conditions, but received different instructions, so it was not possible to combine their results. During the extended time administration, the students who needed more time than the provided were given 20 minutes extra to complete their test, but they were asked to mark the point in the test where they asked for additional time.

The results showed that the learning disabilities group presented a variety in 
the time needed to complete the test (Huesman \& Frisbie, 2000). More specifically, some of the students did not need additional time, others asked for the extra 20-minute accommodation and some performed above the average without any accommodation. In addition, the groups of non-learning disabilities received different directions, with the group who was told to work at their own pace presenting better results compared to the one who was urged to work at a normal pace, under extended conditions. All in all, under the extended time accommodation all groups, except for the NLD group that was instructed to work at a normal pace, presented better results, with the LD students who faced severe reading difficulties showing greater improvement than the other LD and NLD peers (Huesman \& Frisbie, 2000). The researchers concluded that a general accommodation of fixed additional time may not be as effective as the demand of additional time by the ones who need it. In any case, more individualized accommodations based on the learning profile of the students may provide more representative results regarding their performance.

Mandinach, Bridgeman, Cahalan-Laitusis, \& Trapani (2005) conducted a research on the administration of extended time to junior high school students who were identified as typical students, students with learning disabilities and/or ADHD. The Scholastic Aptitude Test (SAT) that was given to all groups included both maths and verbal part, the latter having also reading comprehension exercises. The test was randomly administered to the participants under the standardized time, 1.5 additional time with and without specific timing for the sections and double additional time. The results did not show significant improvement in the performance of the participants with and without disabilities, with the low-ability students gaining the least from this accommodation, since they lacked reading comprehension strategies (Mandinach et al., 2005). However, researchers mentioned that the number of participants with learning disabilities was limited, so as to reach safe conclusions. It was concluded that the most beneficial administration for students both with and without learning disabilities, as far as the verbal part is concerned, was the 1.5 extended time with specific section timing and breaks, which seems to have aided both groups of students achieve slightly better results.

Studies on adults with reading disabilities also support the positive effect of the administration of extended time. In the research of Lesaux, Pearson, \& Siegel (2006), 64 native English speaking adults with and without reading disabilities completed a reading comprehension test (Nelson-Denny Reading Test) under timed (20 minutes) and untimed conditions (40 minutes) and subtests assessing domains such as word recognition and vocabulary knowledge. The participants were divided into average readers, above average readers, below average readers and readers with severe reading disabilities.

The results indicated that the untimed condition benefitted the participants with reading disabilities, with the below average and severe reading disabilities groups presenting greater improvement, even though they had never accepted any intervention (Lesaux, Pearson, \& Siegel, 2006). Nonetheless, the extended 
time accommodation did not lead the severe reading disabilities students, despite their improvement, to achieving the same results as the average readers group. However, the below average readers approached the performance of the average ones. All in all, the researchers suggested the administration of extended time as a favorable accommodation, but they emphasized the need for adaptations on the different types of accommodations according to the distinct characteristics of each disorder and the severity of its symptoms.

Opposing results are presented in the study of Lewandowski, Lovett, \& Rogers (2008) who did not observe statistically significant improvement in the performance of the students with learning disabilities under extended time administration. More specifically, 32 students with learning disabilities (LD) and 32 typical students of $10^{\text {th }}$ to $12^{\text {th }}$ grade participated in the study. Students were asked to complete the comprehension subtest of the Nelson-Denny Reading Test, as far as reading comprehension is concerned, (NDRT; Brown, Fishco \& Hanna, 1993, as cited in Lewandowski, Lovett, \& Rogers, 2008), among cognitive and fluency tests, which were administered under both conditions. It was shown that extended time benefitted non-LD students more than LD students. However, the LD group presented improvement both in terms of the number of test items they managed to answer, since under non-accommodated conditions they managed to answer fewer test items, and the number of the correct answers they gave. LD students managed to complete as many items as their typical peers did, scoring better in the accommodated format than the standard one (Lewandowski, Lovett, \& Rogers, 2008).

\section{Technology Oriented Accommodations}

Along with read-aloud and extended time, technology oriented accommodations that basically include the use of particular software, have started gaining ground, offering significant aid to students with learning disabilities. Schneps, Thomson, Chen, Sonnert, \& Pomplun (2013) investigated the use of e-readers as an accommodation in high school students facing reading disabilities. The sample of the study consisted of 103 high school students with dyslexia, with or without decoding problems and limited attention span, who were randomly assigned into four groups. The literacy profile of the students had been measured by standard tests before the experiment. During the experiment, texts were divided into forms A and B with two levels of difficulty and were given to the participants, who had to read them either on paper or on the I-Pod and then answer multiple choice questions on a sheet of paper. Each group completed the test in a different order as far as the form (A or B) and the means (iPod or paper) are concerned. The procedure was repeated for the two levels of difficulty. Visual attention span was also examined.

The I-Pod offered particular font and setting, Times New Roman pt. 42 with a right-ragged margin and black background with full white or grey display of the text and fewer words per line. Participants were given time in order to get familiarized with the I-Pod so as not to experience difficulties with its use due to the 
lack of practical knowledge. It was concluded that simple presentation modifications such as the font and the length of lines, improved the performance irrespectively of the extent of reading difficulties (Schneps et al., 2013). More specifically, it was shown that through the presentation properties of the iPod, students with decoding problems and poor sight word reading read faster, while participants with limited visual attention span presented improved comprehension, leading to the conclusion that the iPod enhanced their attention and memory deficits (Schneps et al., 2013).

Another research on assistive technology as an accommodation for improving the performance of students with learning disabilities was conducted by Floyd \& Judge (2012). Six postsecondary students were selected after a screening procedure for learning disabilities and more specifically for reading comprehension disabilities. The tool that was used was the ClassMate Reader which enabled the participants to choose the font and the background colour they wish, to listen to the text while it appears on the screen, to adjust the volume and the speed of read-aloud and to use a dictionary to find the meaning and the pronunciation of the words.

The participants first completed the reading comprehension assessment on paper, and then throughout each intervention session, they completed reading comprehension assessment with the aid of the assistive tool. It was concluded that assistive technology and particularly ClassMate reader improved significantly the performance of all the students in the reading comprehension assessment, aiding them surpass the obstacles set by their reading difficulties, no matter their extent (Floyd \& Judge, 2012).

In addition, Dolan et al. (2005), as mentioned before, investigated the effectiveness in test results of a computer-based system with additional text to speech option (CBT-TTS) in the administration of a history and civics test. Along with the optional text to speech accommodation, the computer-based system allowed the highlighting of words that aided participants' reading procedure. Participants also had the opportunity to review their answers through the system if they wished.

The results of the study confirmed the effectiveness of the computer-based system along with the text to speech facility, since students showed significant improvement regarding their performance in texts longer than 100 words. It was also verified by the students' interviews that the text to speech accommodation helped them either in decoding or in comprehension and they expressed a preference for it when comparing it to human read-aloud accommodation (Dolan et al., 2005). Furthermore, researchers also referred to the frequency of using other facilities of the computer-based system; among the most frequent being the review marker and words highlighting which enabled participants regulate their own decisions according to their needs, offering a more individualized approach (Dolan et al., 2005). These possibilities may have also affected the positive results and the positive attitude of participants towards the computer-based system (Dolan et al., 2005). The researchers conclude that further investigation 
is important to show the full potential of a computer-based system, with larger samples and more thorough training in its use (Dolan et al., 2005).

Moreover, Lange, McPhillips, Mulhern, \& Wylie (2006) investigated the effectiveness of four literacy assistive software tools on assessing reading comprehension among other domains (e.g. proofreading). The participants of this study were 93 students (14 - 15 years old) with reading difficulties, information that was obtained after the administration of a standardized reading test (Lange et al., 2006). Three groups were formed; the Assistive Software Group, the Microsoft Control Group and the Full Control Group, with the first two being trained on the corresponding software. The third group received no training. The groups were matched on several variables, such as socioeconomic status, IQ, reading and spelling ability and computer exposure (Lange et al., 2006). All three groups used the Microsoft World with the first group using also the Read \& Write Gold, Version 6 (2002, as cited in Lange et al., 2006) and the second group having access to advanced tools in Microsoft Word. Two standardized reading tests (WORD reading comprehension subtest (Rust et al., 1993, as cited in Lange et al., 2006) and the Neale Analysis of Reading Ability II (Neale, 1997, as cited in Lange et al., 2006) were modified for computer use. The questions of the reading text were all multiple-choice questions. Participants first completed a pretest without the use of any tool, then groups one and two received training on the corresponding tools (including spellchecking, dictionary, homophone and speech synthesis tools), and afterwards they were administered a posttest in which specific subtools of the corresponding software were used for each domain, e.g. reading comprehension or proofreading (Lange et al., 2006).

As far as the reading comprehension part is concerned, the Assistive Tool Group showed more significant improvement than the other two groups, basically due to the speech synthesis tool which compensated for decoding difficulties (Lange et al., 2006). Dictionaries seemed also to have aided the first group, but only those with higher reading scores, whereas the degree of reading difficulty did not reveal statistically significant results in the other two groups (Lange et al., 2006).

Finally, Higgins \& Raskind (2005) investigated the effectiveness of Quicktionary Reading Pen II, a technological device, on reading comprehension of students with learning disabilities. The participants were 30 students, between 10 and 18 years old that were identified as students with learning disabilities. After extensive practice with the device, participants were asked to complete reading comprehension multiple choice exercises from the Formal Reading Inventory (FRI) (Wiederholt, 1986, as cited in Higgins \& Raskind, 2005), under the standard format and the Quiktionary Reading Pen II, the latter offering aid to decoding and to definition of unknown words.

The results of the study confirmed the results of previous studies on assistive technology, since the participants showed improvement both in the number of correct answers but also in the reading of more demanding texts as the test proceeded (Higgins \& Raskind, 2005). Researchers emphasized on the effectiveness 
of assistive technology, however they suggested that further research should be conducted with larger samples and age groups and with students of different levels of aptitude in using technology, since the participants of this research were thoroughly exposed to the specific technological device and this might have affected the results (Higgins \& Raskind, 2005).

\section{Other Accommodations}

Apart from the read-aloud, extended time and technology-oriented accommodations, which seem to gain ground, there are other accommodations which have not been extensively used or researched, focusing on the types of exercises, the scheduling of administration and the cognitive aid provided while completing a test. Below, accommodations such as the aforementioned are being discussed.

Returning to the research of Randall \& Engelhard (2010) on the read-aloud accommodation and resource guide, in $4^{\text {th }}$ and $7^{\text {th }}$ grade students, the effectiveness of the latter will be discussed in more details. The resource guide used in the research included academic definition of words and explanation of the main points of the questions, such as explanation of the terminology e.g. main idea-details, offering scaffolding to students while completing the test. This accommodation led to a slight improvement in the performance only of the typical group and resulted in a decline of the performance of the group with learning disabilities. The aforementioned result might be attributed to the lack of familiarization of the students with the resource guide and the need of having reading competence to use it; a skill in which participants faced significant difficulties (Randall \& Engelhard, 2010).

Furthermore, the research of Fletcher, Francis, Boudousquie, Copeland, Young, Kalinowski, \& Vaughn (2006) examined both the effect of the read aloud accommodation, including the oral presentation of proper nouns and of comprehension stems in the reading comprehension assessment and of multiple sessions, that is the completion of the test into two blocks of time instead of one (Fletcher et al., 2006). The participants of the study attended the $3^{\text {rd }}$ grade and were average or poor decoders. Participants were given the Texas reading accountability assessment under the standard or the accommodated format. The results of the research confirmed the interaction theory, since students with decoding difficulties benefitted from the accommodation, while average decoders did not present any significant improvement (Fletcher et al., 2006). However, the performance of poor readers did not approach the one of average readers (Fletcher et al., 2006). Despite the positive effects of the accommodations, it is not possible to understand if one of the three accommodations or their combination led to the improved results.

In addition, Fletcher, Francis, O'Malley, Copeland, Mehta, Caldwell, Kalinowski, Young, \& Vaughn (2009) conducted a research on a package of accommodations administered to more than 100 students of $7^{\text {th }}$ grade, including read aloud of stems, answers and proper nouns in the administration of the modified 
for research purposes TAKS test (Texas Assessment of Knowledge and Skills, as cited in Fletcher et al., 2009), along with the accommodation of the test's completion in one or two days. Poor and average readers were identified through testing and randomly assigned to three groups, each completing the TAKS under one of the three formats, the standard format, the read aloud format completed within one day and the read aloud completed within two days (Fletcher et al., 2009). The test included both narrative and expository texts with multiple choice and open questions.

The results of the research showed that poor readers presented improved performance in both types of accommodations, with the two-day administration presenting the best results (Fletcher et al., 2009). The aforementioned finding leads to the assumption that multiple day accommodation provided participants with more positive results than the read aloud one, as it enabled students to limit fatigue, which often obstructs them from organizing their thought and strategies (Fletcher et al., 2009). On the other hand, since all participants had completed a state administered TAKS test as part of the educational procedure, before the administration of the three formats of the same test for the purposes of the research, the following comparison is enabled. Specifically, the average readers presented no statistically significant improvement in the accommodated formats compared to the state-administered test, whereas the average readers completing the standard format during the experimental procedure presented lower performance compared to the state-administered test, probably due to the lack of motivation in completing the same test under low-stake conditions (Fletcher et al. 2009). The latter finding obstructs the researchers from verifying the interaction theory through the results of this research.

Contrary to the above findings, Walz, Albus, Thompson, \& Thurlow (2000) reported no improvement under the multiple-day accommodation on the part of students with disabilities. The study was conducted in two urban and two rural schools. The participants were 112 students with and without learning disabilities (64 students of general education and 48 of special education), from $7^{\text {th }}$ and $8^{\text {th }}$ grade, some of them not having English as a home language (Walz et al., 2000). The Minnesota Basic Standard Test was the pool of the study's test items (Walz et al., 2000). All students were administered the standard form (one day administration) and the accommodated form (three day administration) without any other familiar to participants accommodation, such as the absence of a separate answer sheet (Walz et al., 2000). Special education and general education students were divided into four groups and completed the test under both forms but different administration order.

The results of the research did not support the interaction theory since students with learning difficulties performed lower than typical students in both forms (Walz et al., 2000). Furthermore, all groups showed better results under the one day administration, with the general education groups presenting lower instead of statistically stable performance under the three day accommodation (Walz et al., 2000). The researchers suggest more research on different test 
lengths, since in this research the three-day administration involved the completion of one text with 10 multiple choice questions which was considered too short to provoke fatigue and reveal the full potential of the accommodation (Walz et al., 2000). They also suggest the use of other accommodations, which are familiar to students, along with the multiple day accommodation, and a more homogeneous linguistic profile (Walz et al., 2000).

Finally, De Kida, De Avila, \& Capellini (2016) evaluated reading comprehension through oral retelling not as an accommodation but as an alternative way to assess reading comprehension of students with dyslexia and language based learning disability (LBLD). This particular change in the assessment evaluates participants' comprehension both at micro level, that is the number of ideas that are retold, and macro level, the relevance and the meaningful links between the ideas of the text, according to their schooling age. The participants were 105 elementary school students from $2^{\text {nd }}$ to $5^{\text {th }}$ grade. They were divided into six groups, group of students with dyslexia and LBLD, their corresponding control groups and two groups paired with the dyslexic and LBLD groups as regards reading accuracy. The texts that were used in the study were four expository texts of unknown topics to students in order to minimize previous knowledge effects. Participants were asked to read the texts either silently or aloud and they were not given a specific amount of time for the completion of the procedure. The retelling was recorded so as to be analyzed in the aftermath.

It was concluded that the groups presenting learning disabilities did not approach the performance of typical students due to the difficulties created by their learning profile (De Kida, De Avila, \& Capellini, 2016). However, the dyslexic students presented better results in retelling compared to LBLD students who faced severe difficulties in all aspects of linguistic competence, supporting the conclusions on the distinct learning profile of each disorder and verifying the need for specific differentiations according to the specific characteristics of each disability (De Kida, De Avila, \& Capellini, 2016). It was also verified that retelling aided the dyslexic group perform better than the paired accuracy group as far as macro level is concerned, suggesting that decoding difficulties can be compensated both by linguistic competence and more exposure to reading (De Kida, De Avila, \& Capellini, 2016). Nevertheless, retelling as a way of assessing reading comprehension presents limitations and is not appropriate for all kinds of disorders and age groups.

\section{Discussion and Directions for Future Research}

As shown in the studies reviewed, the most frequent accommodations as far as reading comprehension assessment for students with learning disabilities is concerned are extended time and read aloud accommodation. Other accommodations were also discussed but to a limited extent, since there is a restricted number of experimental studies as regards their effectiveness. However, they offer some useful data which can be used by researchers in order to further inves- 
tigate the effectiveness of accommodations, other than the "extended time" and "read aloud" ones, as regards the improvement of reading comprehension skills of students with learning disabilities. Such accommodations refer to differentiated types of exercises, technology oriented accommodations, scheduling accommodations and provision of cognitive aid while completing a test; differentiations that focus not only on the way of administering the test but also on the test items themselves.

On a practical basis, this review provides teachers with helpful insights as regards the variety of existing accommodations and their efficiency. Firstly, knowing the variety of accommodations and their validity which is proven by scientific research, will allow teachers to choose the most appropriate one for specific difficulties and age groups, without questioning the validity of their students' performance. It is quite often that teachers are not aware of the variety of existing accommodations and that they do not implement the ones they know for fear that they might affect the validity of students' results. In addition, the interaction theory provides support on the use of accommodations for the whole classroom instead of students with learning disabilities, enabling teachers to solve problems of objections on an alleged favorable format available only to a specific group of students. Finally, the accommodations analyzed refer both to high-stake national examinations and school exams, enabling their administration during summative assessment so that teachers receive a more accurate picture of their students' performance. The aforementioned procedures will lead to the creation of an educational system that provides students with learning disabilities with all the means for academic advancement both in terms of teaching and in terms of assessment, since the difficulties that students with learning disabilities face regulate all the aspects of the educational procedure.

On academic level, the findings of the studies reviewed are ambivalent as far as the verification of the interaction theory is concerned, since some accommodations led to improvement of the performance of students both with and without learning disabilities, supporting the need for more research. In the majority of the studies, this improvement was greater but not exclusive to students with learning disabilities promoting a differentiation in the definition of the interaction theory that puts emphasis on the extent of the performance improvement and not on the absence of improvement in the performance of typical students (Sireci, Li, \& Scarpati, 2003). On the other hand, there are also studies, such as Fletcher et al. (2006) research, the results of which support the interaction theory, since their findings show an improvement in the performance only of students with learning disabilities and not of typical students under the accommodated conditions.

More specifically, the majority of the studies reviewed favor a differentiated definition of the interaction theory which supports a differential boost as far as the improvement of the performance of the participants is concerned. This differential boost hypothesis (Fuchs \& Fuchs, 1999, as cited in Gregg \& Nelson, 
2012) proposes a less strict version of the interactive theory, which puts emphasis on the extent of improvement under the differentiated assessment and not the lack of it. It is supported that accommodations should lead LD students to more significant improvement than their typical peers (Gregg \& Nelson, 2012). The aforementioned theory has been supported by the majority of the studies reviewed, such as Huesman \& Frisbie (2000), and Weston (2002) studies.

However, a significant number of studies that focused on technology oriented accommodations, such as Higgins \& Raskind (2005) research, and other accommodations apart from the read-aloud and extended time accommodations, included only LD participants, so it was not possible to discuss the effectiveness of these accommodations in the light of the interaction theory. Moreover, the studies of Kosciolek \& Ysseldyke (2000), Brown \& Augustine (2001) and Elbaum, Arguelles, Campbell, \& Saleh (2004) showed no statistically significant improvement for either group as far as the differentiated administration is concerned. Finally, there were mixed results concerning the read-aloud and extended time accommodations as regards whether they led to performance improvement of all students, LD students or neither type of students.

Consequently, more research is needed with samples that include both typical students and students with learning disabilities through which the validity of the interaction theory will be assessed and probably the need for a less strict version of it will emerge. In addition, due to the fact that the majority of the studies referred to a sample that was labeled as "group with learning disabilities", it would be significant for future research to examine test accommodations on samples diagnosed with a specific disorder, such as specific reading disability, so that a conclusion is reached on which accommodations are more effective than others for each particular disorder. Such research would demonstrate appropriate test differentiations that would cater for each student's learning profile, according to the distinct characteristics each disorder presents. Finally, studies that will assess only one accommodation at a time may present clearer results as to which type of accommodation is more effective. It is supported that when a combination of accommodations is used, clear conclusions cannot be drawn as to the contribution of each separate accommodation to the improvement of the performance of students with learning disabilities (Fuchs et al., in press, as cited in Fletcher et al., 2006). Therefore, studies on distinct accommodations will provide us with clearer insights on their effectiveness on particular deficits and skills.

\section{Conflicts of Interest}

The authors declare no conflicts of interest regarding the publication of this paper.

\section{References}

Alexander-Passe, N. (2006). How Dyslexic Teenagers Cope: An Investigation of SelfEsteem, Coping and Depression. Dyslexia, 12, 256-275. https://doi.org/10.1002/dys.318

Brown, P. J., \& Augustine, A. (2001). Screen Reading Software as an Assessment Ac- 
commodation: Implications for Instruction and Student Performance. The Annual Meeting of the American Educational Research Association, Seattle, 10-14 April 2001.

Crawford, L., \& Tindal, G. (2004). Effects of a Read-Aloud Modification on a Standardized Reading Test. Exceptionality, 12, 89-106. https://doi.org/10.1207/s15327035ex1202_3

De Kida, A., De Ávila, C., \& Capellini, S. (2016). Reading Comprehension Assessment through Retelling: Performance Profiles of Children with Dyslexia and Language-Based Learning Disability. Frontiers in Psychology, 7, 1-13. https://doi.org/10.3389/fpsyg.2016.00787

Dermitzaki, I., Andreou, G., \& Paraskeva, V. (2008). High and Low Reading Comprehension Achievers' Strategic Behavior and Its Relation to Performance in Reading Comprehension. Reading Psychology, 29, 471-492. https://doi.org/10.1080/02702710802168519

Dolan, R. P., Hall, T. E., Banerjee, M., Chun, E., \& Strangman, N. (2005). Applying Principals of Universal Design to Test Delivery: The Effect of Computer-Based read Aloud on Test Performance of High School Students with Learning Disabilities. Journal of Technology, Learning, and Assessment, 4, 4-32.

https://ejournals.bc.edu/ojs/index.php/jtla/issue/archive

Eide, B., \& Eide, F. F. (2006). The Mislabeled Child. New York: Hyperion.

Elbaum, B., Arguelles, M. E., Campbell, Y., \& Saleh, M. B. (2004). Effects of a Student-Reads-Aloud Accommodation on the Performance of Students with and without Learning Disabilities on a Test of Reading Comprehension. Exceptionality, 12, 71-87. http://www.fmuniv.edu/pdf/campbell_read_alound_accomodation.pdf

Fletcher, J. M., Francis, D. J., O’Malley, K., Copeland, K., Mehta, P., Caldwell, C. J., Kalinowski, S., Young, V., \& Vaughn, S. (2009). Effects of a Bundled Accommodations Package on High-Stakes Testing for Middle School Students with Reading Disabilities. Exceptional Children, 75, 447-463. https://doi.org/10.1177/001440290907500404

Fletcher, J., Francis, D., Boudousquie, E., Copeland, K., Young, V., Kalinowski, S., \& Vaughn, S. (2006). Effects of Accommodations on High-Stakes Testing for Students with Reading Disabilities. Exceptional Children, 72, 136-150. https://doi.org/10.1177/001440290607200201

Floyd, K. K., \& Judge, S. L. (2012). The Efficacy of Assistive Technology on Reading Comprehension for Postsecondary Students with Learning Disabilities. Assistive Technology Outcomes and Benefits, 8, 48-64. https://www.learntechlib.org/p/114207/.

Gregg, N., \& Nelson, M. (2012). Meta-Analysis on the Effectiveness of Extra Time as a Test Accommodation for Transitioning Adolescents with Learning Disabilities: More Questions than Answers. Journal of Learning Disabilities, 45, 128-138. https://doi.org/10.1177/0022219409355484

Harley, T. (2014). The Psychology of Language: From Data to Theory (4 ${ }^{\text {th }}$ ed.). New York: Psychology Press.

Helland, T., \& Kaasa, R. (2005). Dyslexia in English as s Second Language. Dyslexia, 11, 41-60. https://doi.org/10.1002/dys.286

Higgins, E. L., \& Raskind, M. H. (2005). The Compensatory Effectiveness of the Quicktionary Reading Pen II on the Reading Comprehension of Students with Learning Disabilities. Journal of Special Education Technology, 20, 29-38. http://www.wizcom-text.com/Research/Documents/Frostig\%20Study\%20-\%20JSET.pdf

Huesman, R. L., \& Frisbie, D. (2000). The Validity of ITBS Reading Comprehension Test Scores for Learning Disabled and Non Learning Disabled Students under ExtendedTime Conditions. In The Annual Meeting of the National Council on Measurement in 
Education.

Hulme, C., \& Snowling, M. (2011). Children's Reading Comprehension Difficulties: Nature, Cause and Treatments. Current Directions in Psychological Science, 20, 139-142. https://doi.org/10.1177/0963721411408673

Kosciolek, S., \& Ysseldyke, J. E. (2000). Effects of a Reading Accommodation on the Validity of a Reading Test (Technical Report 28). Minneapolis, MN: University of Minnesota, National Center on Educational Outcomes. http://education.umn.edu/NCEO/OnlinePubs/Technical28.htm

Kuhn, M., Schwanenflugel, P., \& Meisinger, E. (2010). Aligning Theory and Assessment of Reading Fluency: Automaticity, Prosody, and Definitions of Fluency. Reading Research Quality, 45, 232-253. https://doi.org/10.1598/RRQ.45.2.4

Lange, A. A., McPhillips, M., Mulhern, G., \& Wylie, J. (2006). Assistive Software Tools for Secondary-Level Students with Literacy Difficulties. Journal of Special Education Technology, 21, 13-22. https://doi.org/10.1177/016264340602100302

Lesaux, N. K., Pearson, M. R., \& Siegel, L. S. (2006). The Effects of Timed and Untimed Testing Conditions on the Reading Comprehension Performance of Adults with Reading Disabilities. Reading and Writing, 19, 21-48.

https://doi.org/10.1007/s11145-005-4714-5

Lewandowski, L. J., Lovett, B. J., \& Rogers, C. L. (2008). Extended Time as a Testing Accommodation for Students with Reading Disabilities: Does a Rising Tide Lift All Ships? Journal of Psychoeducational Assessment, 26, 315-324. https://doi.org/10.1177/0734282908315757

Mandinach, E. B., Bridgeman, B., Cahalan-Laitusis, C. C., \& Trapani, C. (2005). The Impact of Extended Time on SAT Test Performance. College Board Research Report No. 2005-8.

https://www.ets.org/research/policy_research_reports/publications/report/2005/hzdq

Meloy, L., Deville, C., \& Frisbie, D. (2000). The Effects of a Reading Accommodation on Standardized Test Scores of Learning Disabled and Non Learning Disabled Students. New Orleans, LA: National Council on Measurement in Education Annual Meeting.

Randall, J., \& Engelhard, G. (2010). Performance of Students with and without Disabilities under Modified Conditions. Journal of Special Education, 44, 79-93.

https://doi.org/10.1177/0022466908331045

Schneider, C., Gong, B., \& Egan, K. (2016). Testing Accommodations for Students with Dyslexia: Key Opportunities to Understand Student Thinking.

https://www.nciea.org/library/testing-accommodations-students-dyslexia-key-opportu nities-understand-student-thinking

Schneps, M. H., Thomson, J. M., Chen, C., Sonnert, G., \& Pomplun, M. (2013). E-Readers Are More Effective than Paper for Some with Dyslexia. PLoS ONE, 8, e75634. https://doi.org/10.1371/journal.pone.0075634

Shaywitz, S. E., \& Shaywitz, B. A. (2005). Dyslexia (Specific Reading Disability). Biological Psychiatry, 57, 1301-1309. https://doi.org/10.1016/j.biopsych.2005.01.043

Sireci, S. G., Li, S., \& Scarpati, S. (2003). The Effects of Test Accommodations on Test Performance: A Review of the Literature. Center for Educational Assessment Research Report No. 485. Amherst, MA: School of Education, University of Massachusetts, Amherst.

Thurlow, M., Lazarus, S., Thompson, S., \& Morse, A. B. (2005). State Policies on Assessment Participation and Accommodations for Students with Disabilities. The Journal of Special Education, 38, 232-240. https://doi.org/10.1177/00224669050380040401

Torgesen, J. K. (2006). Recent Discoveries from Research on Remedial Interventions for 
Children with Dyslexia. In M. Snowling, \& C. Hulme (Eds.), The Science of Reading: A Handbook. Oxford: Blackwell Publishers.

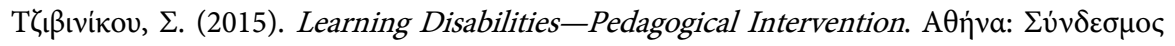

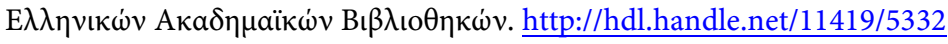

Walz, L., Albus, D., Thompson, S., \& Thurlow, M. (2000). Effect of a Multiple Day Test Accommodation on the Performance of Special Education Students (Minnesota Report No. 34). Minneapolis, MN: University of Minnesota, National Center on Educational Outcomes.

https://nceo.info/Resources/publications/OnlinePubs/archive/AssessmentSeries/MnRe port34.html

Weston, T. J. (2002). The Validity of Oral Accommodation in Testing. NAEP Validity Studies (NVS) Panel (NCES 200306). Washington DC: National Center of Education Statistics.

Zimmerman, B. J. (2002). Becoming a Self-Regulated Learner: An Overview. Theory into Practice, 41, 64-70. https://doi.org/10.1207/s15430421tip4102_2

http://mathedseminar.pbworks.com/w/file/fetch/94760840/Zimmerman\%20-\%202002 \%20-\%20Becoming\%20a\%20Self-Regulated\%20Learner\%20An\%20Overview.pdf 